\author{
Helmut Zedelmaier
}

\title{
Werkstätten des Wissens zwischen Renaissance und Aufklärung
}

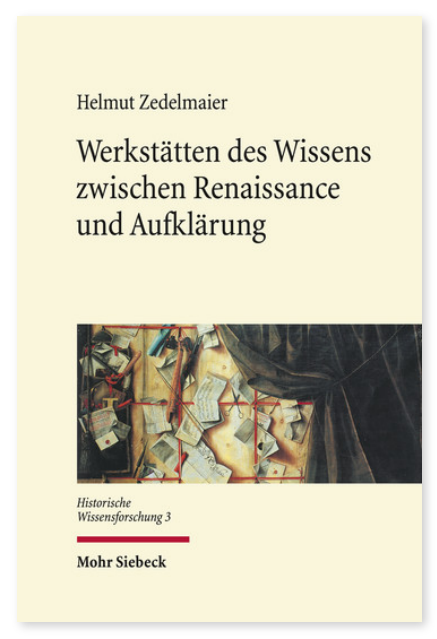

2015. VI, 167 Seiten (m. zahlreichen Abbildungen). HWF 3

ISBN 978-3-16-153935-0

DOI 10.1628/978-3-16-153935-0

eBook PDF 59,00€

ISBN 978-3-16-153807-0

fadengeheftete Broschur 59,00€
Suchmaschinen vermitteln uns im globalen Netz Informationen sekundenschnell. Wie wir Informationen suchen, wie wir lesen und das Gelesene verarbeiten, hat sich radikal verändert. Einem ebenso tiefgreifenden Wandel sind die Agenturen und Institutionen unterworfen, die Wissen aufbereiten, es in Bewegung setzen und verkaufen. Die Erfahrung von Veränderung schärft die historische Aufmerksamkeit für alltägliche Praktiken der Wissensproduktion, ihre historischen Kontexte und Transformationen. Helmut Zedelmaier untersucht Wissenspraktiken von Gelehrten zwischen Renaissance und Aufklärung. Welche Techniken und Methoden nutzten sie, um gesuchte Informationen zu finden? Wie haben sie ihr Wissen verwaltet und verarbeitet? Welche Kräfte und Kontexte bewirkten in diesem Zeitraum Veränderungen der Praktiken und Institutionen der Wissensproduktion? Heutige Visionäre digitaler Wissenswelten wollen uns davon überzeugen, dass wir uns in eine Gesellschaft hineinbewegen, in der immer mehr Menschen immer mehr wissen. Löst man sich von der Fixierung auf das bloße Wachstum von Daten und deren digitale Verarbeitungsmöglichkeiten, zeigt sich die beschränkte Erklärungskraft von einfachen Fortschrittsgeschichten. Auch darum geht es dem Autor: um die historische Relativierung der viel beschworenen »digitalen Revolution«, die vieles von ihrem revolutionären Charakter verliert, lässt man sich genauer auf die buchgestützte Welt und ihre Werkstätten ein. Wissen war damals und ist noch heute ein vermitteltes Produkt, das nicht einfach vorliegt, das sich nicht bloß aus Einsichten und Ideen ergibt. Wissen ist immer auch ein Produkt, das historisch wandelbaren Praktiken und Werkzeugen unterliegt, die eher anonym wirksam und deshalb schwer fassbar sind.

Helmut Zedelmaier Studium der Geschichte, Germanistik, Politik und Soziologie; 1989 Promotion; 1996 Habilitation in Neuerer Geschichte; seit 2004 außerplanmäßiger Professor an der Ludwig-Maximilians-Universität München.
Jetzt bestellen:

https://mohrsiebeck.com/buch/werkstaetten-des-wissens-zwischen-renaissance-und-aufklaerung-9783161539350? no_cache=1

order@mohrsiebeck.com

Telefon: +49 (0)7071-923-17

Telefax: +49 (0)7071-51104 